\begin{tabular}{|c|l|}
\hline Title & Importance of specific hydrogen bonds of archaeal rhodopsins for the binding to the transducer proteint \\
\hline Author(s) & $\begin{array}{l}\text { Sudo, Y uki; Y amabi, Masaki; Kato, Shinnosuke; Hasegawa, Chisa; Iwamoto, Masay uki; Shimono, Kazumi; Kamo, } \\
\text { Naoki }\end{array}$ \\
\hline Citation & $\begin{array}{l}\text { JOURNAL OF MOLECULAR BIOLOGY, 357(4), 1274-1282 } \\
\text { https://doi.org/L0.1016/.jmb.2006.01.061 }\end{array}$ \\
\hline Issue Date & 2006-04_07 \\
\hline Doc URL & http://hdl.handle.net/2115/10532 \\
\hline Type & article (author version) \\
\hline File Information & JMB01687_2.pdf \\
\hline
\end{tabular}

Instructions for use 
(JMB revised; D-05-01687)

\title{
Importance of specific hydrogen bonds of archaeal rhodopsins for the binding to the transducer protein ${ }^{\dagger}$
}

\author{
Yuki Sudo, ",\# \$ Masaki Yamabi, " Shinnosuke Kato, " Chisa Hasegawa, ${ }^{\#}$ \\ Masayuki Iwamoto, ${ }^{\ddagger}$ " \# Kazumi Shimono, ${ }^{\%, ~ \# ~ a n d ~ N a o k i ~ K a m o " ~}$
}

Laboratory of Biophysical Chemistry, Graduate School of Pharmaceutical Sciences, Hokkaido University, Sapporo 060-0812, Japan, Division of Molecular

Physiology and Biophysics, Department of Morphological and Functional Biomedical Science, Faculty of Medical Science, University of Fukui, Matsuoka 910-1193, Japan, RIKEN Genomic Sciences Center, 1-7-22 Suehiro-cho, Tsurumi,Yokohama 230-0045, Japan

Running Title: A transducer binding to four archaeal rhodopsins

Key words: photo-sensor, protein-protein interaction, ion pump, sensory rhodopsin, phoborhodopsin

${ }^{\dagger}$ This work was supported by grants from the Japanese Ministry of Education, Culture, Sports, Science, and Technology, Japan.

\footnotetext{
\# Hokkaido University

${ }^{\ddagger}$ University of Fukui

\% RIKEN Genomic Sciences Center

\$ Present address: Department of Applied Chemistry, Nagoya Institute of Technology, Showa-ku, Nagoya 466-8555, Japan
} 
* To whom correspondence should be addressed. Phone and Fax: 81-52-735-5207. E-mail: yuki_sudo@hotmail.com

\section{Footnotes}

${ }^{1}$ Abbreviations: N. pharaonis, Natronomonas pharaonis; $H$. salinarum, Halobacterium salinarum; bR, bacteriorhodopsin from $H$. salinarum; hR, halorhodopsin from $N$. pharaonis; sR, sensory rhodopsin from $H$. salinarum; pR, phoborhodopsin from N. pharaonis; Htrll, halobacterial transducer protein II from N. pharaonis; ITC, isothermal titration calorimetry; $\mathrm{K}_{\mathrm{D}}$, dissociation constant; DDM, n-dodecyl- $\beta$-D-maltoside 


\section{ABSTRACT}

Four rhodopsins, bacteriorhodopsin (bR), halorhodopsin $(h R)$, sensory rhodopsin (sR) and phoborhodopsin (pR) exist in archaeal membranes. bR and $\mathrm{hR}$ work as a light-driven ion pump. $\mathrm{sR}$ and $\mathrm{pR}$ work as a photo-sensor of phototaxis, and form signaling complexes in membranes with their respective cognate transducer proteins Htrl (with $\mathrm{sR}$ ) and Htrll (with $\mathrm{pR}$ ), through which light signals are transmitted to cytoplasm. What is the determining factor(s) of the specific binding to form the complex? Binding of the wild or mutated rhodopsins with Htrll was measured by Isothermal titration calorimetric analysis (ITC). bR and hR could not bind with Htrll. On the other hand, SR could bind to Htrll, although the dissociation constant (KD) was about 100-times larger than that of pR. X-ray crystallographic structure of the $\mathrm{pR} / \mathrm{Htrll}$ complex (Gordeliy et al. Nature $419,484-487)$ revealed the formation of two specific hydrogen bonds

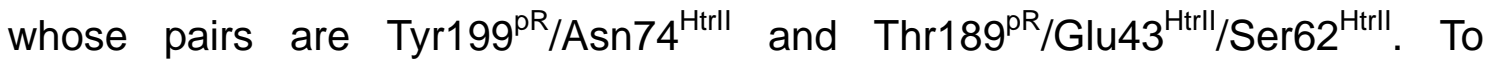
investigate the importance of these hydrogen bonds, the $K_{D}$ for the binding of various mutants of $b R, h R, s R$ and $p R$ with Htrll was estimated by ITC. The KD value of $\mathrm{T} 189 \mathrm{~V}^{\mathrm{DR}} / \mathrm{Y} 199 \mathrm{~F}^{\mathrm{pR}}$, double mutant/Htrll complex, was about 100 -fold larger than that of the wild-type $p R$ whose $K_{D}$ value was $0.16 \mu \mathrm{M}$. On the other hand, bR and hR double mutants, $\mathrm{P} 200 \mathrm{~T}^{\mathrm{bR}} / \mathrm{V} 210 \mathrm{Y}^{\mathrm{bR}}$ and $\mathrm{P} 240 \mathrm{~T}^{\mathrm{hR}} / \mathrm{F} 250 \mathrm{Y}^{\mathrm{hR}}$, were able to bind with Htrll. The KD value of these complexes was estimated to be $60.1 \pm 10.7 \mu \mathrm{M}$ for $\mathrm{bR}$ and to be $29.1 \pm 6.1 \mu \mathrm{M}$ for $\mathrm{hR}$ while the wild $\mathrm{bR}$ and hR did not bind with Htrll. We concluded that these two specific hydrogen bonds played important roles in the binding between the rhodopsins and transducer protein. 


\section{INTRODUCTION}

Many organisms utilize light as energy source and as a signal. Retinal proteins (rhodopsins) have retinal as a chromophore and exist in various organisms; i.e., archaea, eubacteria, and eukaryotes (1-4). The archaeon Halobacterium salinarum, halophilic prokaryote, contains four retinal proteins (rhodopsins), i.e., bacteriorhodopsin (bR) (5), halorhodopsin (hR) (6), sensory rhodopsin (sR, also called sensory rhodopsin I, SRI) (7) and phoborhodopsin (pR, also called sensory rhodopsin II, sRII) (8) (see Fig. 1). Functionally, these proteins are distinctly different. The function of $b R$ and $h R$ is a light-driven outward proton pump and a light-driven inward chloride pump, respectively. SR and $\mathrm{pR}$ work as light-sensitive photo-receptors, and they form a signaling complex in archaeal membranes with their cognate transducer proteins, Htrl and Htrll, respectively (7-9) (Fig. 1). These complexes transmit the light signal to a cytoplasmic part of the transducer to activate the phosphorylation cascades that modulate the flagellum motors (10). The transducer ( $\mathrm{Htrl}$ or Htrll) is a two-transmembrane helical protein that belongs to a family of methyl-accepting chemotaxis proteins (MCPs) $(11,12)$. MCP exists as a homodimer composed of a 50-60 kDa subunit and forms a ternary complex with CheA and CheW. Using this signaling system, the bacterium can avoid harmful near-UV light (negative phototaixis) or can be attracted to longer wavelength light where bR and hR can utilize light energy (positive phototaxis) (7-9).

Spudich and co-workers obtained evidence showing that the signal transfer between the receptor ( $\mathrm{sR}$ or $\mathrm{pR}$ ) and its respective cognate $\mathrm{Htr}$ ( $\mathrm{Htrl}$ or HtrlI) was proceeded by the trans-membranous region; they made a variety of chimeras of Htr's which were composed of the trans-membranous and cytoplasmic part of two Htr's (9). Only when the correct pair of receptor and its cognate trans-membranous helix was formed, the phototaxis was observed. 
What is the specificity of the interaction between the rhodopsin receptors and transducers? Previously, we examined amino acid residues that may be important to the binding of the $\mathrm{pR}$ with Htrll whose complex catalyzes the negative phototaxis from blue-green light $(\sim 500 \mathrm{~nm})$, and the importance of Asp193 ${ }^{\mathrm{pR}}$, Thr204 ${ }^{\mathrm{pR}}$ and the linker region of Htrll have been shown (13-15). However, the contribution of these residues to the binding was low, and therefore another factor(s) is important for the specific binding between the rhodopsin and the transducer. The x-ray crystallographic structure of the $\mathrm{pR} / \mathrm{Htrll}$ complex reveals the formation of two hydrogen bonds whose pairs are Tyr199 ${ }^{\mathrm{pR}} /$ Asn74 ${ }^{\mathrm{Htrll}}$ and Thr189 ${ }^{\mathrm{pR}} /{\text { Glu} 43^{\mathrm{Htrll}} / \text { Ser62 }}^{\text {Htrll }}$ (16) (Fig. 2). In this paper, we demonstrate that these two hydrogen bonds play important roles in the binding between the rhodopsins and transducer protein. In addition, it is shown that $\mathrm{bR}$ and $\mathrm{hR}$ that originally cannot bind with Htrll become able to bind when hydrogen-bond forming amino acid residues are introduced at the proper positions of rhodopsins.

\section{MATERIALS AND METHODS}

\section{Protein expression and purification}

Expression plasmids for bR, hR (from Natronomonas pharaonis), $\mathrm{pR}$ (from $\mathrm{N}$. pharaonis) and Htrll (from N. pharaonis) were constructed as previously described (17-20). The plasmid including a full-length sop (the gene of sensory rhodopsin) with a fusing histidine tag was prepared by PCR using genomic DNA from the $H$. salinarum strain R1, as described in Ref 21. PCR was carried out using two oligonucleotide primers introducing a 5'-Ndel (sense primer) and 3'-Xhol (antisense primer) restriction site. The stop codon was deleted during amplification. A PCR product containing the sop gene was obtained, purified, and subcloned into a plasmid vector pGEM-T Easy (Promega, Madison, WI). 
The construction of the expression plasmid is essentially the same as that previously described $(20,22)$.

All mutant genes were constructed by PCR using the QuickChange site-directed mutagenesis method. The oligonucleotide primers were designed from nucleotide sequences in the Genbank database. The DNA obtained was sequenced using a DNA sequencing kit (Applied Biosystems, Foster City, CA). All the constructed plasmids were analyzed using an automated sequencer (377 DNA sequencer, Applied Biosystems).

All proteins including mutant proteins were expressed in E. coli BL21 (DE3) cells $(17,20)$. The preparation of crude membranes and purification of the proteins were performed using essentially the same method as previously described $(17,22)$. The sample was concentrated by ultrafiltration (UK-50, Adantech, Tokyo, Japan) and completely exchanged by dialysis (15) against media. Its composition was typically $300 \mathrm{mM} \mathrm{NaCl}, 10 \mathrm{mM}$ Tris- $\mathrm{HCl}(\mathrm{pH}$ 8.0) and $0.05 \%$ n-dodecyl- $\beta$-D-maltoside (DDM), but for sR, $4 \mathrm{M} \mathrm{NaCl}$ was used instead of $300 \mathrm{mM} \mathrm{NaCl}$.

\section{Analysis of Htrll-induced thermal stabilization}

Absorption spectra were taken using a Model V-560 spectrometer (Jasco, Tokyo, Japan). The temperature was kept at the desired value by circulating thermostated water, and the temperature inside the cuvette was directly measured with a thermocouple. The activities of various rhodopsins (bR, $\mathrm{hR}, \mathrm{sR}$ and $\mathrm{pR}$ ) after incubation at high temperature were estimated from the absorbance of $\lambda \max$ (23). During incubation, the suspension became turbid, maybe due to the aggregation by denatured proteins. Therefore, before the spectral measurement, the sample was briefly centrifuged at 15,000 $\mathrm{g}$ for $1 \mathrm{~min}$ to remove the aggregated protein. This method is easy to examine whether 
rhodopsins can bind with the transducer, but does not give $K_{D}$ values. Hence, this method was used in this paper as an auxiliary method to confirm the ability of binding or no binding deduced by ITC.

\section{Isothermal titration calorimetry (ITC) measurement}

For ITC experiments, the rhodopsins (bR, hR, sR and $p R$ ) and Htrll solutions were completely exchanged by dialysis against the buffer solution described above for 1 week using a 3-kDa cutoff dialysis cassette. All ITC experiments were performed using a VP-ITC Micro Calorimeter (Microcal Inc., Studio City, CA). For the control experiments, DDM-buffer solutions $(0.05 \%)$ without proteins were used to ensure no effect caused by the detergent. The binding parameters were estimated using the following binding scheme:

Rhodopsin $(\mathrm{bR}, \mathrm{hR}, \mathrm{sR}$ and $\mathrm{pR}) / \mathrm{Htrll} \mathrm{n} \longleftrightarrow$ rhodopsin $+\mathrm{n} \mathrm{Htrll}$ where $\mathrm{n}$ represents the number of Htrll molecules required for the formation of the complex with rhodopsin. Data were evaluated by employing an Origin-ITC software package.

\section{RESULTS}

\section{Binding between the wild-type rhodopsin (bR, $h R, s R$ or $p R)$ and Htrll}

In an effort to determine whether Htrll binds with four retinal proteins, $b R, h R, s R$ and $p R$, we performed ITC measurements (see the Materials and Methods and ref. 15). Previously, Engelhard and co-workers reported that the dissociation constant of $\mathrm{pR} / \mathrm{Htrll}$ complex was quantitatively estimated using ITC (24). Figure 3 shows titration curves of the wild-type $b R, h R$, sR and $p R$ with Htrll. In these experiments, $b R, h R$ and $p R$ and $s R$ were maintained at 318 or $308 \mathrm{~K}$, and these rhodopsin solutions were added to the Htrll solution in increments of $10 \mu \mathrm{L}$ using a syringe. Measurement for sR was performed at 308 
$\mathrm{K}$ and in the presence of a high salt concentration $(4 \mathrm{M} \mathrm{NaCl})$ because they aggregated at temperatures over $313 \mathrm{~K}$ and in a lower salt concentration (1 M $\mathrm{NaCl}<$ ) (25). The effect of temperature on the dissociation constants was neglected for the case of either 318 or $308 \mathrm{~K}$, because of the small $(3 \%)$ difference in the temperatures. Other thermodynamic quantities were calculated under the consideration of the temperature (see Table 1). The dissociation constants of the sR/Htrll and pR/Htrll complexes were estimated as $12.6 \pm 1.8$ and $0.16 \pm 0.06 \mu \mathrm{M}$, respectively, whereas $\mathrm{bR}$ and $\mathrm{hR}$ showed neither a release nor uptake of heat (Fig. 3), suggesting no binding activity with Htrll.

At high temperature, the time-dependent color loss of $\mathrm{pR}$, denaturation, was observed, and we reported that Htrll retarded the denaturation rate of $p R$ in a previous paper (23). It was shown that the increase in the thermal stability was a good estimation method for the binding activity in spite of being semi-quantitative. The increase in the Htrll-induced thermal stability of sR was detected, whereas the increases were not observed for $\mathrm{bR}$ and $\mathrm{hR}$ (data not shown). The results of both ITC and the thermal stability clearly show that bR and $\mathrm{hR}$ cannot bind with Htrll whereas the receptor proteins, $\mathrm{sR}$ and $\mathrm{pR}$, can bind with Htrll. Note that the binding of $\mathrm{SR}$ with Htrll is weak by the factor of about 2 orders, because Htrll is not a primary partner.

\section{Importance of the Thr189 and Tyr199 position of receptors (sR and pR) for}

\section{the binding with Htrll}

The $\mathrm{x}$-ray crystallographic structure of the $\mathrm{pR} / \mathrm{Htrll}$ complex reveals the formation of two specific hydrogen bonds between Tyr $199^{\mathrm{pR}}$ and Asn74 ${ }^{\mathrm{Htrll}}$ and between Thr189 ${ }^{\mathrm{pR}}$ and Glu43 ${ }^{\mathrm{Htrll}} / \mathrm{Ser} 62^{\mathrm{Htrll}}$ (Fig. 2) (16). Figure 4 (right panels) shows the titration curves of $\mathrm{T} 189 \mathrm{~V}^{\mathrm{pR}} / \mathrm{Y} 199 \mathrm{~F}^{\mathrm{pR}}$ mutant $\mathrm{pR}$ with Htrll. Note that in this mutant, hydrogen-bonding amino acid residues were replaced. The 
dissociation constant $\left(K_{D}\right)$ of this complex increased by nearly two orders (9.9 from $0.16 \mu \mathrm{M}$ ) and was almost identical to that of the signaling complex, i.e. the complex between M-intermediate of $p R\left(p_{M}\right)$ and $\mathrm{Htrl}(15 \mu \mathrm{M})(20)$. This result clearly suggests that these two hydrogen bonds are very important for the binding between $\mathrm{pR}$ and Htrll. The $\mathrm{K}_{\mathrm{D}}$ values of a $\mathrm{T} 189 \mathrm{~V}^{\mathrm{pR}}$ and a $\mathrm{Y}_{199 \mathrm{~F}^{\mathrm{pR}}}$ single mutant were estimated as $0.73 \pm 0.17$ and $0.35 \pm 0.10 \mu \mathrm{M}$, respectively. In these experiments, temperature was maintained at $318 \mathrm{~K}$.

The similar experiment using SR was carried out. $K_{D}$ values of $F 199 Y^{s R}$ (corresponding to Tyr199 ${ }^{\mathrm{pR}}$ ) and $\mathrm{T}_{189 \mathrm{~V}^{\mathrm{SR}}}$ (corresponding to Thr189 ${ }^{\mathrm{pR}}$ ) single

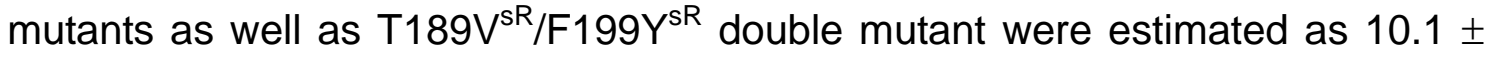
3.8, $22.3 \pm 3.4$ and $56.6 \pm 10.7 \mu \mathrm{M}$, respectively (left panels in Fig. 4 and summarized in Fig. 6). As described above, a $K_{D}$ value of the wild-type $s R$ is $12.6 \mu \mathrm{M}$, which is larger than that of $\mathrm{F} 199 \mathrm{Y}^{\mathrm{sR}}$, because an amino acid residue of the wild-type sR corresponding to Thr $189^{\mathrm{pR}}$ is Thr, and hence F199Y ${ }^{\mathrm{SR}}$ has two hydrogen bond-forming amino acid residues. The $K_{D}$ values of the various mutants and the number of hydrogen bonds putatively formed are well correlated (Fig. 6).

\section{Binding of mutant $b R$ and $h R$ in which two hydrogen-bonding amino acid residues are introduced}

We further tried to reveal the importance of these two hydrogen bonds. As described above, bR neither $\mathrm{hR}$ can bind to Htrll (or the $\mathrm{K}_{\mathrm{D}}$ values are too large to be determined by ITC). What happened when the hydrogen bonding amino acid residues were introduced into these ion-pumping rhodopsins? Figure 5(a) shows the titration curves of $\mathrm{P}_{200 \mathrm{~T}^{\mathrm{bR}}}$ (corresponding to Thr189 $^{\mathrm{pR}}$ ), V210Y ${ }^{\mathrm{bR}}$ (corresponding to Tyr199 ${ }^{\mathrm{pR}}$ ), $\mathrm{P}^{240 \mathrm{~T}^{\mathrm{hR}}}$ (corresponding to Thr189 ${ }^{\mathrm{pR}}$ ) and $\mathrm{F} 250 \mathrm{Y}^{\mathrm{hR}}$ (corresponding to Tyr199 ${ }^{\mathrm{pR}}$ ) mutants with Htrll. These four 
mutants of bR and hR do not show any heat flow (Fig. 5 (a)), suggesting no binding activity with Htrll. No binding was also detected by the Htrll-induced thermal stabilization (data not shown). The $K_{D}$ values of these mutants may be greater than $>300 \mu \mathrm{M}$ because the detectable limitation of the heat changes is about $>300 \mu \mathrm{M}$.

Of interest, the binding of mutants having two hydrogen bonding

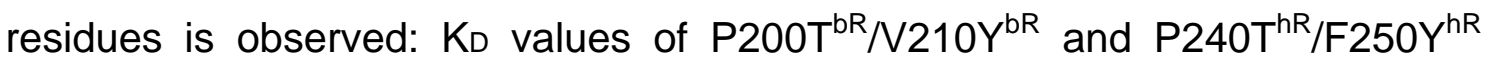
mutants were estimated as $60.1 \pm 10.7$ and $29.1 \pm 6.1 \mu \mathrm{M}$, respectively (Fig. 5 (b)). Consistently, the Htrll-induced thermal stability changes of the

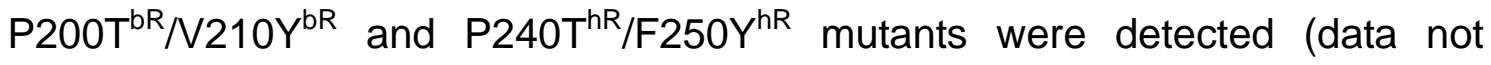
shown).

\section{DISCUSSION}

The X-ray structure (16) shows that three hydrogen bonds between $\mathrm{pR}$ and Htrll are formed at two amino acid residues of $\mathrm{pR}$, whose pairs are Tyr199 ${ }^{\mathrm{pR}} /$ Ans $74^{\mathrm{Htrll}}$, Thr189 ${ }^{\mathrm{pR}} / \mathrm{Glu} 43^{\mathrm{Htrll}}$ and Thr189 ${ }^{\mathrm{pR}} /$ Ser62 ${ }^{\mathrm{Htrl}}$. Using mutants of $\mathrm{pR}$ at the $199^{\text {th }}$ and/or the $189^{\text {th }}$ position, this paper proved this experimentally. Hippler-Mreyen et al. (24) reported that the hydrogen bond formed between the phenolic group of Tyr $199^{\mathrm{pR}}$ and $\mathrm{Asn} 74^{\mathrm{Htrll}}$ has only a minor contribution to the


value of the wild-type $\mathrm{pR} / \mathrm{Htrll}$ complex $(0.16 \mu \mathrm{M})$. They assumed that the phenolic ring - phenolic ring interaction between Tyr $199^{\mathrm{pR}}$ and Phe $28^{\mathrm{Htrll}}$ is important for the interaction between $\mathrm{pR}$ and Htrll. The existence of this phenolic ring - phenolic ring $(\pi-\pi)$ interaction was also suggested in our previous paper (23). The present result argues against the primary importance of this phenolic ring - phenolic ring $(\pi-\pi)$ interaction for the binding: If this interaction exerts primarily to bind, no significant increase in $K_{D}$ should be 


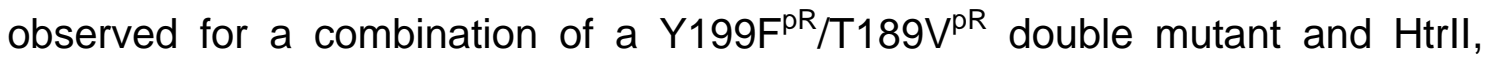
because the phenolic ring - phenolic ring interaction is still alive. As is seen from $p R$ data in Fig. 6, the large increase in $K_{D}$ values is observed only when pR protein is mutated simultaneously at both sites. We further did the similar experiment using a Htrll mutant, S62 $A^{H t r l l}$. The $K_{D}$ value of $9.5 \mu M$ for a

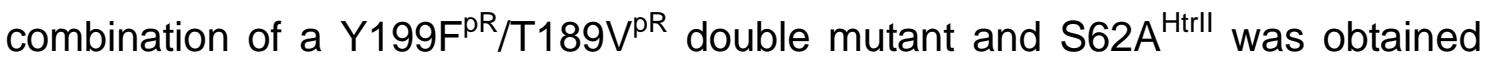
while $K_{D}$ value for a combination of a $T 189 V^{p R}$ single mutant and $S 62 A^{H \text { trll }}$ was $0.7 \mu \mathrm{M}$ in which the hydrogen bond at Tyr199 was possibly formed (compare $0.16 \mu \mathrm{M}$ of the wild-type combination). This indicates the importance of the hydrogen bond at the Tyr199 position of pR. From these observations together with the results of Hippler-Mreyen et al. (24), we assume as follows: In the case where the hydrogen bond forms between Thr189 ${ }^{\mathrm{pR}}$ and Glu43 ${ }^{\mathrm{Htrll}} / \mathrm{Ser} 62^{\mathrm{Htrll}}$, the phenolic ring $\left(\right.$ Tyr199 $\left.{ }^{\mathrm{pR}}\right)$ - phenolic ring $\left(\right.$ Phe28 $\left.{ }^{\mathrm{Htrll}}\right)$ interaction works instead of the hydrogen bonds although the ring-ring interaction may be weak in comparison with the hydrogen bond. On the other hand, in the case where the hydrogen bond breaks between Thr189 ${ }^{\mathrm{pR}}$ and Glu43 ${ }^{\mathrm{Htrll}} / \mathrm{Ser} 62^{\mathrm{Htrll}}$, the hydrogen bond between Tyr199 ${ }^{\mathrm{pH}}$ and Asn74 ${ }^{\text {Htrll }}$ becomes important instead of the ring-ring interaction. In this sense, the hydrogen bond between Thr189 ${ }^{\mathrm{pR}}$ and Glu43 ${ }^{\mathrm{Htrll}} /$ Ser62 $2^{\mathrm{Htrll}}$ might be more important than that between Tyr199 ${ }^{\mathrm{pH}}$ and Asn $74^{\mathrm{Htrll}}$, which may be stemmed from the formation of two hydrogen bonds.

The similar story might be accepted for sR: the $K_{D}$ value of SR (Thr189, Tyr199), $10.1 \mu \mathrm{M}$, was changed to a small increase to $12.6 \mu \mathrm{M}$ due to the mutation of the $199^{\text {th }}$ position, while the mutation at the $189^{\text {th }}$ position induced larger increase in the $K_{D}$ value (from 10.1 to $22.3 \mu \mathrm{M}$ ) as shown in Fig. 6. On the other hand, for $\mathrm{bR}$ and $\mathrm{hR}$, the simultaneous formation of the hydrogen bonds at the two positions seems indispensable.

Are not the hydrophobic and/or van der Waals interactions important? 


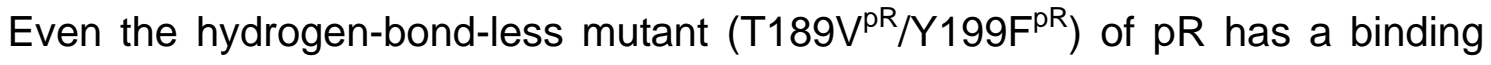
activity with Htrll (Fig. 4 and 6) although the binding is about 100-times weaker. Of interest, bR and hR mutants (P200T ${ }^{\mathrm{bR}} / \mathrm{V} 210 \mathrm{Y}^{\mathrm{bR}}$ and $\left.\mathrm{P} 240 \mathrm{~T}^{\mathrm{hR}} / \mathrm{F} 250 \mathrm{Y}^{\mathrm{hR}}\right)$ can bind with Htrll in spite of the weaker binding than that of the wild-type pR/Htrll complex (Fig. 6). These results suggest that the hydrophobic and/or van der Waals interaction is also important for the binding between rhodopsins and transducers. Note that the X-ray structure $(16,26)$ shows intimate contact between pR and Htrll; The helix 2 of Htrll is nested in the groove formed by helices $F$ and $G$ of $p R$ (see later discussion).

Table 1 lists the thermodynamic values of the binding. Hippler-Mreyen et al. obtained the thermodynamic data of the binding between pR and Htrll (24). Their values are $\Delta \mathrm{G}=-41.35 \mathrm{~kJ} \mathrm{~mol}^{-1}, \Delta \mathrm{H}=-17.9 \mathrm{~kJ} \mathrm{~mol}^{-1}$ and $\Delta \mathrm{S}=73.74 \mathrm{~J}$ $\mathrm{mo}^{\mathrm{l}-1} \mathrm{~K}^{-1}$. In comparison with Table $1, \Delta \mathrm{G}$ values of both are almost the same while $\Delta \mathrm{H}$ of our data is larger by about $11 \mathrm{~kJ} \mathrm{~mol}^{-1}$ (absolute value) and hence the value of the entropy change is different each other. The reason for this difference is not known at present. Table 1 indicates that values of $\Delta \mathrm{G}$ for bR, $h R$, sR and their mutants are contributed almost from $\Delta \mathrm{H}$ changes, suggesting that the formation of the hydrogen bonds is the main origin of the binding. On the other hand, the data of pR show large entropy changes and less contribution of $\Delta \mathrm{H}$ to $\Delta \mathrm{G}$ than those of other rhodopsins. The exact reason is not known at present. However, a possible reason is: Formation of the hydrogen bonds put $\mathrm{pR}$ and Htrll together. Since both the interface surfaces of these proteins match geometrically each other (26), the bound lipids or detergent molecules may be squeezed out from the binding interface, which leads to an increase in $\Delta \mathrm{S}$ and a change in $\Delta \mathrm{H}$. This intimate contact will result in the strong binding.

During the photocycling of $\mathrm{pR}$, how do these hydrogen bonds change? 
This is an interesting and important question to be investigated. Recently, we applied Fourier transform infrared (FTIR) spectroscopy to the active $M$ intermediate of $\mathrm{pR}$ in the absence and presence of $\mathrm{HtrlI}(27,28)$. We found that the hydrogen bond of Asn $74^{\mathrm{Htrll}}$ is strengthened in $\mathrm{M}$, because of the change in the interaction with Tyr $199^{\mathrm{pR}}$. However, Bergo et al. reported the disappearance of the hydrogen bond in the $M$ and $O$ photointermediates (29). Thus, the conclusion on this point is controversial yet, but it is certain that the hydrogen bonding between rhodopsins and Htrll is important not only for the binding at the ground state but also for the signal transfer reaction from $\mathrm{pR}$ to Htrll. Previously, we reported that the signal transduction from $\mathrm{pR}$ to Htrll accompanies a weakened binding in the M-state of $p R(30,31)$. As pointed out above, Tyr199 ${ }^{\mathrm{pR}}$ forms hydrogen bonds with Asn74 ${ }^{\text {Htrll }}$ not only in the ground state, but also in the active M-state $(20,30)$ (although the opposite observation (29) was reported). Hence, the hydrogen bonds between Thr189 ${ }^{\mathrm{pR}}$ and Glu43 ${ }^{\text {Htrll }} /$ Ser62 ${ }^{\text {Htrll }}$ should be broken at M-state or weakened so that the interaction between the receptor and the transducer becomes weak. Thus, two hydrogen bonds may play different roles for the signal transduction through the photocycling. This point should be awaited for a further detailed investigation.

In this study, we show that $\mathrm{bR}, \mathrm{hR}$ and $\mathrm{SR}$ can also potentially bind with Htrll if the proper amino acid residues are introduced to form hydrogen bonds with Htrll. We previously reported that $\mathrm{pR}$ has a proton pumping activity, whereas the pR/Htrll complex could not pump (30). In the case of $s R$, it was reported that the removal of Htrl allows electrogenic proton transfer by SR (31, 32). Therefore, following questions arise: Do the bR (double mutant)/Htrll and $\mathrm{hR}$ (double mutant)/Htrll complexes have the ion-pumping activity? Do the $\mathrm{sR} / \mathrm{Htrll}$ and pR (double mutant)/Htrll complex have a photo-signal transfer activity? Can we make a protein that has both pumping activity and photo-signal 
transfer activity? These are our next focus. In addition, we should examine whether these two hydrogen bonds may change during photocycling and if it is the case, how these changes would contribute the signal transduction.

\section{ACKNOWLEDGMENT}

We thank Dr. Harumi Fukada for her expert technical assistance with the ITC measurements and Dr. Seiji Miyauchi for his stimulus discussions. 


\section{REFERENCES}

(1) Oesterhelt, D. (1998) Curr. Opin. Struct. Biol. 8, 489-500.

(2) Beja, O., Aravind, L., Koonin, E. V., Suzuki, M. T., Hadd, A., Nguyen, L. P., Jovanovich, S. B., Gates, C. M., Feldman, R. A., Spudich, J. L., et al. (2000) Science 289, 1902-1906.

(3) Bieszke, J. A., Braun, E. L., Bean, L. E., Kang, S., Natvig, D. O., \& Borkovich, K. A. (1999) Proc. Natl. Acad. Sci. USA 96, 8034-8039.

(4) Spudich, J.L., Yang, C-S., Jung, K-H., \& Spudich, E.N. (2000) Annu. Rev. Cell Biol. 16, 365-392.

(5) Lanyi, J. K., \& Luecke, H. (2001) Curr. Opin. Struct. Biol. 11, 415-419.

(6) Essen, L. O. (2002) Curr. Opin. Struct. Biol. 12, 516-522.

(7) Hoff, W.D., Jung, K.H., \& Spudich, J.L. (1997) Annu. Rev. Biophys. Biomol. Struct. 26, 223-258.

(8) Sudo, Y., Kandori, H., \& Kamo, N. (2004) Recent Res. Devel. Biophys. 3, 1-16.

(9) Zhang, X. N., Zhu, J., \& Spudich, J. L. (1999) Proc. Natl. Acad. Sci. USA 96, 857-862.

(10) Rudolph, J. \& Oesterhelt, D. (1996) J. Mol. Biol. 258, 548-554.

(11) Rudolph , J. , Nordmann , B. , Storch , K. F. , Gruenberg , H. , Rodewald , K., \& Oesterhelt , D. (1996) FEMS Microbiol. Lett. 139, 161-168.

(12) Falke, J. J., Bass, R. B., Butler, S. L., Chervitz, S. A., \& Danielson, M. A. (1997) Annu. Rev. Cell Dev. Biol. 13, 457-512.

(13) Sudo, Y., Iwamoto, M., Shimono, K., \& Kamo, N. (2004) Biochemistry 43, 13748-13754.

(14) Sudo, Y., Furutani, Y., Shimono, K., Kamo, N., \& Kandori, H. (2003) Biochemistry 42, 14166-14172. 
(15) Sudo, Y., Okuda, H., Yamabi, M., Fukuzaki, Y., Mishima, M., Kamo, N., \& Kojima, C. (2005) Biochemistry 44, 6144-6152.

(16) Gordeliy, V. I., Labahn, J., Moukhametzianov, R., Efremov, R., Granzin, J., Schlesinger, R., Buldt, G., Savopol, T., Scheidig, A. J., Klare, J. P., et al. (2002) Nature 419, 484-487.

(17) Shimono, K., Iwamoto, M., Sumi, M., \& Kamo, N. (1997) FEBS Lett. 420, 54-56.

(18) Shimono, K., Hayashi, T., Ikeura, Y., Sudo, Y., Iwamoto, M., \& Kamo, N. (2003) J. Biol. Chem. 278, 23882-23889.

(19) Sato, M., Kanamori, T., Kamo, N., Demura, M., \& Nitta, K. (2002) Biochemistry 41, 2452-2458.

(20) Sudo, Y., Iwamoto, M., Shimono, K., \& Kamo, N. (2001) Photochem. Photobiol. 74, 489-494.

(21) Charlebois, R., Hofman, J.D., Schalkwyk, L. C., Lam, W. L., \& Doolittle, W. F. (1989) Can. J. Microbiol. 35, 21-29.

(22) Kandori, H., Shimono, K., Sudo, Y., Iwamoto, M., Shichida, Y., \& Kamo, N. (2001) Biochemistry 40, 9238-9246.

(23) Sudo, Y., Yamabi, M., Iwamoto, M., Shimono, K., \& Kamo, N. (2003) Photochem. Photobiol. 78, 511-516.

(24) Hippler-Mreyen, S., Klare, J. P., Wegener, A. A., Seidel, R., Herrmann, C., Schmies, G., Nagel, G., Bamberg, E., \& Engelhard, M. (2003) J. Mol. Biol. 330, 1203-1213.

(25) Schmies, G., Chizhov, I., \& Engelhard M. (2000) FEBS Lett. 466, 67-69.

(26) Spudich, J. (2002) Nature struct. biol. 11, 797-799.

(27) Furutani, Y., Iwamoto, M., Shimono, K., Kamo, N., \& Kandori, H. (2002) Biophys. J. 83, 3482-3489.

(28) Furutani, Y., Kamada, K., Sudo, Y., Shimono, K., Kamo, N., \& Kandori, 
H. (2005) Biochemistry 44, 2909-2915.

(29) Bergo, V.B., Spudich, E.N., Rothschild, K.J., \& Spudich, J.L. (2005) J. Biol. Chem. 280, 28365-2869.

(30) Sudo, Y., Iwamoto, M., Shimono, K., \& Kamo, N. (2002) Biophys. J. 83, 427-432.

(30) Sudo, Y., Iwamoto, M., Shimono, K., Sumi, M., \& Kamo, N. (2001) Biophys. J. 80, 916-922.

(31) Olson, K. D., \& Spudich, J. L. (1993) Biophys. J. 65, 2578-2585.

(32) Bogomolni, R. A., Stoeckenius, W., Szundi, I., Perozo, E., Olson, K. D., \& Spudich, J. L. (1994) Proc. Natl. Acad. Sci. USA 91, 10188-10192. 
Table 1. Thermodynamic parameters for the binding of various wild-type or mutants of rhodopsins with Htrll

\begin{tabular}{|c|c|c|c|c|}
\hline & $\begin{array}{l}K_{D} \\
(\mu M)\end{array}$ & $\begin{array}{c}\Delta \mathrm{G} \\
\left(\mathrm{kJ} \mathrm{mol}{ }^{-1}\right)\end{array}$ & $\begin{array}{c}\Delta \mathrm{H} \\
\left(\mathrm{kJ} \mathrm{mol}{ }^{-1}\right)\end{array}$ & $\begin{array}{c}-\mathrm{T} \Delta \mathrm{S} \\
\left(\mathrm{kJ} \mathrm{mol}^{-1}\right)\end{array}$ \\
\hline $\mathrm{bR}$ & $>300$ & ND & ND & ND \\
\hline bR(P200T) & $>300$ & ND & ND & ND \\
\hline bR(V210Y) & $>300$ & ND & ND & ND \\
\hline bR(P200T/V210Y) & 60.1 & -25.7 & -24.2 & -1.5 \\
\hline $\mathrm{hR}$ & $>300$ & ND & ND & ND \\
\hline hR(P240T) & $>300$ & ND & ND & ND \\
\hline hR(P250Y) & $>300$ & ND & ND & ND \\
\hline hR(P240T/P250Y) & 29.1 & -27.6 & -23.4 & -4.2 \\
\hline $\mathrm{sR}$ & 12.6 & -28.9 & -28.4 & -0.5 \\
\hline sR(T189V) & 56.6 & -25.1 & -26.3 & +1.2 \\
\hline sR(F199Y) & 10.1 & -29.5 & -29.7 & +0.2 \\
\hline sR(T189V/F199Y) & 22.3 & -27.4 & -27.2 & -0.2 \\
\hline $\mathrm{pR}$ & 0.16 & -41.4 & -29.3 & -12.1 \\
\hline pR(T189V) & 0.73 & -37.4 & -28.4 & -9.0 \\
\hline $\mathrm{pR}(\mathrm{Y} 199 \mathrm{~F})$ & 0.35 & -39.3 & -28.4 & -10.9 \\
\hline pR(T189V/Y199F) & 9.9 & -30.5 & -25.9 & -4.1 \\
\hline
\end{tabular}

The temperature was $318 \mathrm{~K}$ for bR, hR, pR and their mutants, and was $308 \mathrm{~K}$ for sR and its mutants. The medium contained $300 \mathrm{mM} \mathrm{NaCl}, 10 \mathrm{mM}$ Tris- $\mathrm{HCl}$ (pH 8.0) and $0.05 \% \mathrm{n}$-dodecyl- $\beta$-D-maltoside (DDM), but for sR, $4 \mathrm{M} \mathrm{NaCl}$ was used instead of $300 \mathrm{mM} \mathrm{NaCl}$. ND means not detectable due to the very weak binding. 


\section{FIGURE LEGENDS}

\section{FIGURE 1}

Four retinal proteins in membranes of Halobacterium salinarum. The membrane contains rhodopsins (retinal proteins) such as bacteriorhodopsin (bR), halorhodopsin (hR), sensory rhodopsin (sR) and phoborhodopsin (pR), and two transducer proteins, Htrl and Htrll. Here, bR and $\mathrm{hR}$ work as a light-driven proton pump and a halogen ion pump, respectively, while $\mathrm{SR}$ and $\mathrm{pR}$ work as a photo-sensors, and form signaling complex with its cognate transducer protein, Htrl and Htrll, respectively. These photo-receptors transmit light signals to Htrl or Htrll in the membrane. Htrl or Htrll that forms a ternary complex with CheA and CheW activates phosphorylation cascade that modulate flagella motors. By using these signaling systems, this bacterium cells move toward longer wavelength light $(\lambda>520 \mathrm{~nm})$ where bR and hR work, while they avoid shorter wavelength light $(\lambda<520 \mathrm{~nm})$, which contains harmful near-UV light.

\section{FIGURE 2}

X-ray crystallographic structure of the binding interface of $\mathrm{pR} / \mathrm{Htrll}$ complex. The structure was obtained from the Protein Data Bank (PDB code 1H2S) (16), and this figure reveals the formation of two specific hydrogen bonds between Tyr199 $^{\mathrm{pR}}$ and Asn74 ${ }^{\mathrm{Htrll}}$ (enclosed by a purple box) and between Thr189 ${ }^{\mathrm{pR}}$ and Glu43 ${ }^{\mathrm{Htrll}} /$ Ser62 $2^{\mathrm{Htrll}}$ (enclosed by a yellow box). The numbers in smaller font are the length between respective amino acid residues. Previous results showed that $A s p 193^{\mathrm{pR}}$, Th204 ${ }^{\mathrm{pR}}$ and linker region of Htrll is important for the binding between $\mathrm{pR}$ and Htrll. The membrane normal is roughly in the vertical plane of this figure, and the top and bottom regions correspond to the extracellular and cytoplasmic sides, respectively. 


\section{FIGURE 3}

Isothermal titration calorimetry data of binding of the wild-type $\mathrm{bR}, \mathrm{hR}, \mathrm{sR}$ and pR with Htrll. The upper panels represent raw data. The lower panels represent the enthalpy changes per mole plotted as a function of the molar ratio of rhodopsins to Htrll. The solid lines represent best-fit curves. The determined binding parameters are listed in Table 1 and Figure 6. Published data of the wild type $\mathrm{pR}$ are reproduced from Ref. 15. Experiments were done three times and the average was taken. Details in the experimental conditions are in Materials and Methods

\section{FIGURE 4}

Isothermal titration calorimetry data for binding of $\mathrm{F} 199 \mathrm{Y}^{\mathrm{SR}}$ (correspond to Tyr199 ${ }^{\mathrm{PR}}$ ) and $\mathrm{T} 189 \mathrm{~V}^{\mathrm{PR}} / \mathrm{Y}_{199 \mathrm{~F}^{\mathrm{pR}}}$ mutant with Htrll. The upper panels represent raw data. The lower panels represent the enthalpy changes per mole plotted as a function of the molar ratio of photo-receptor rhodopsins to Htrll. The solid lines represent best-fit curves. The determined binding parameters are listed in Table 1 and Figure 6. Experiments were done three times and the average was taken. Details in the experimental conditions are in Materials and Methods

\section{FIGURE 5}

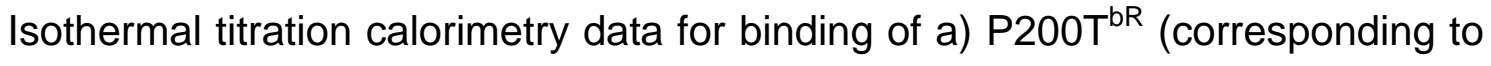
Thr189 ${ }^{\mathrm{pR}}$ ), V210Y $\mathrm{Y}^{\mathrm{bR}}$ (corresponding to Tyr199 ${ }^{\mathrm{PR}}$ ), $\mathrm{P}^{240 \mathrm{~T}^{\mathrm{hR}}}$ (corresponding to Thr189 ${ }^{\mathrm{pR}}$ ) and $\mathrm{F} 250 \mathrm{Y}^{\mathrm{hR}}$ (corresponding to Tyr199 ${ }^{\mathrm{DR}}$ ) mutants with Htrll, and of b) $\mathrm{P} 200 \mathrm{~T}^{\mathrm{bR}} / \mathrm{V} 210 \mathrm{Y}^{\mathrm{bR}}$ and $\mathrm{P} 240 \mathrm{~T}^{\mathrm{hR}} / \mathrm{F} 250 \mathrm{Y}^{\mathrm{hR}}$ mutants with Htrll. The upper panels of a) and b) respectively represent raw data. The lower panels of a) and b) represent the enthalpy changes per mole plotted as a function of the molar ratio of rhodopsins to Htrll. The solid lines represent best-fit curves. 
Experiments were done three times and the average was taken. Details in the experimental conditions are in Materials and Methods. The determined binding parameters are listed in Fig. 6.

\section{FIGURE 6}

The dissociation constants of the binding of $\mathrm{bR}, \mathrm{hR}, \mathrm{sR} \mathrm{pR}$ and their mutants with Htrll. From the left to right on the abscissa, the points stand for (1) rhodopsins that have Thr and Tyr residues at the positions corresponding to $189^{\mathrm{PR}}$ and $199^{\mathrm{pR}}$, respectively, (2) rhodopsins that have Thr at the position corresponding to $189^{\mathrm{pR}}$, (3) the rhodopsins that have Tyr at the position corresponding to $199^{\mathrm{pR}}$ and (4) the rhodopsins that do not have both Thr and Tyr at the positions corresponding to $189^{\mathrm{DR}}$ and $199^{\mathrm{PR}}$, respectively. 
FIGURE 1

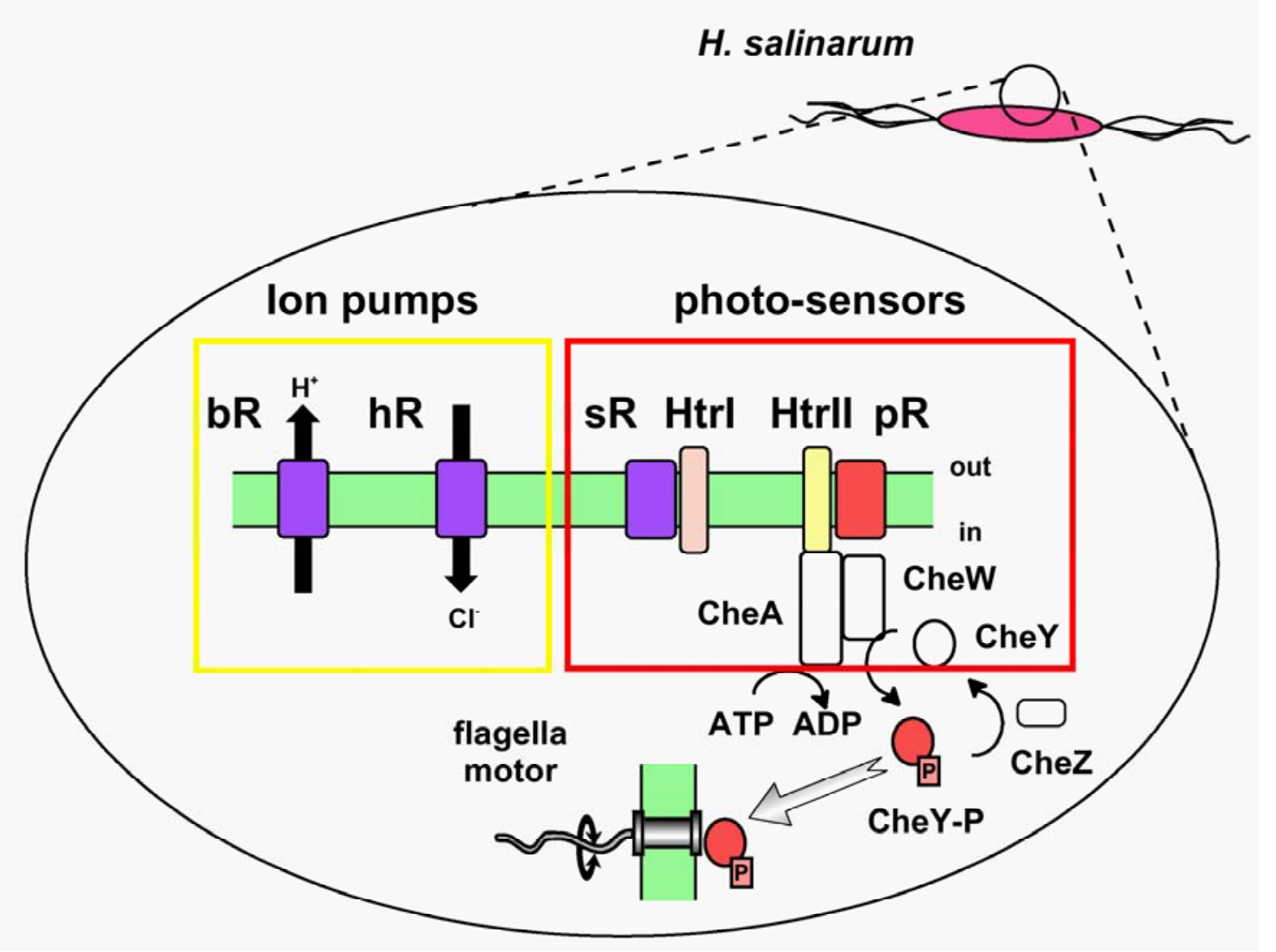

Sudo et al. 


\section{FIGURE 2}

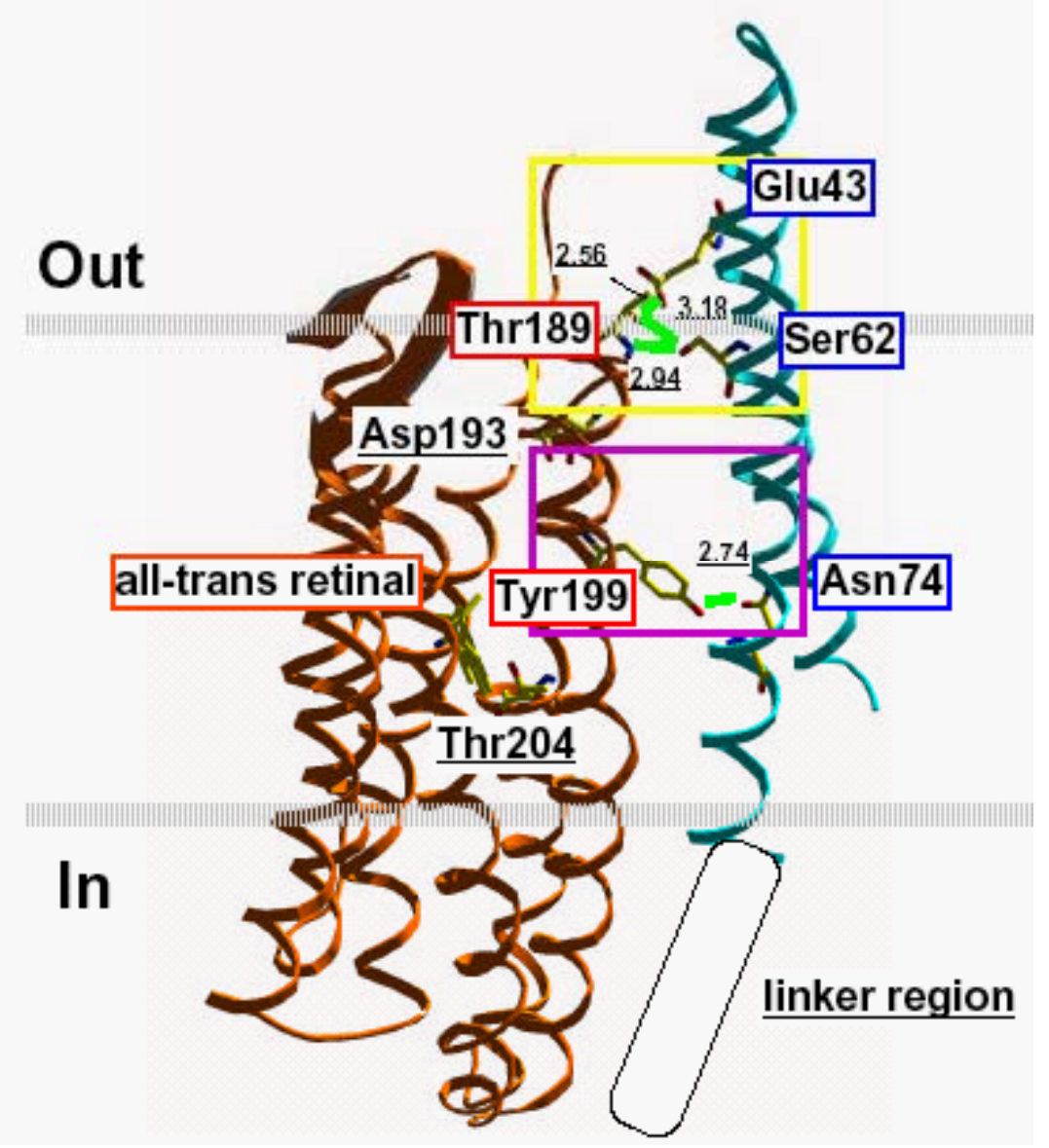




\section{FIGURE 3}
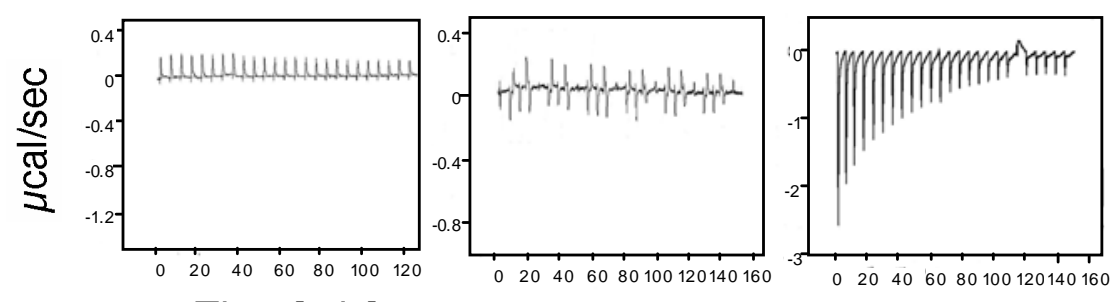

Time [min]

Time [min]
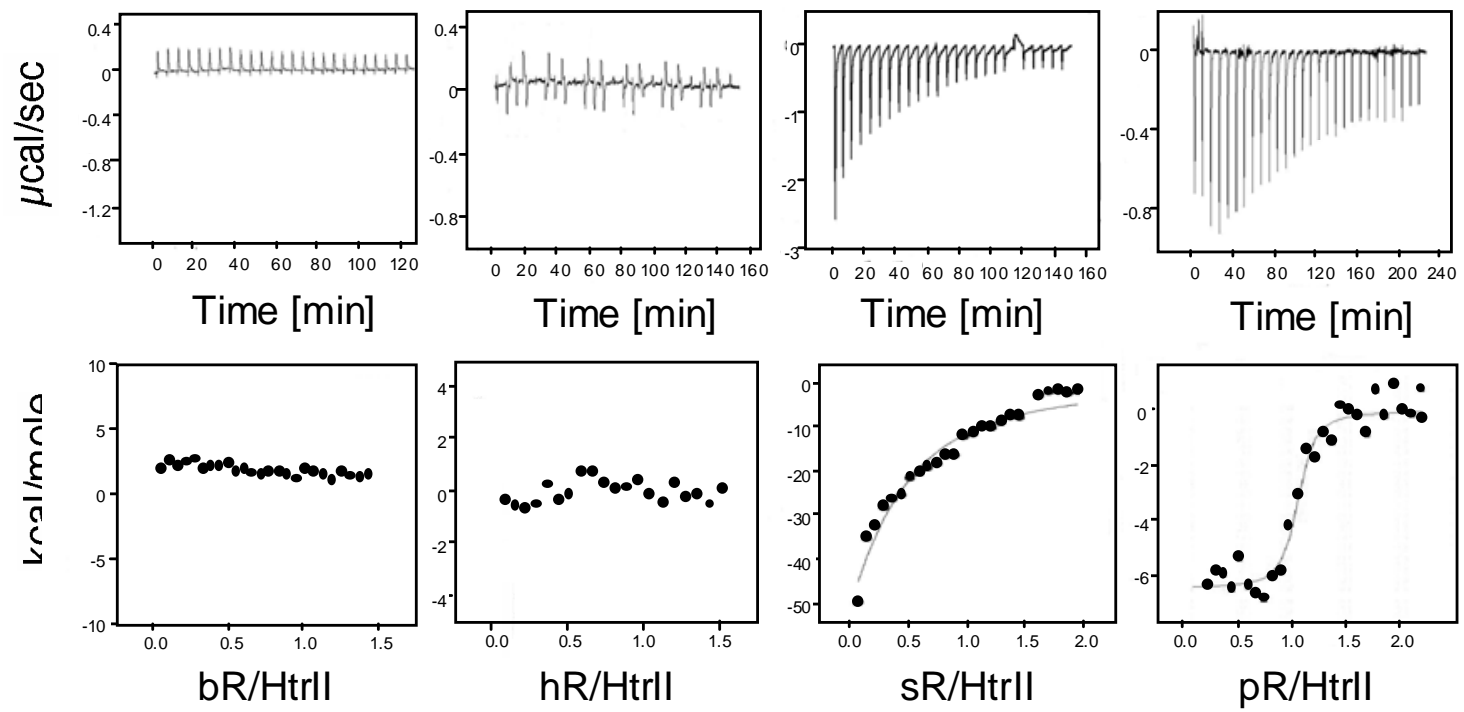
FIGURE 4
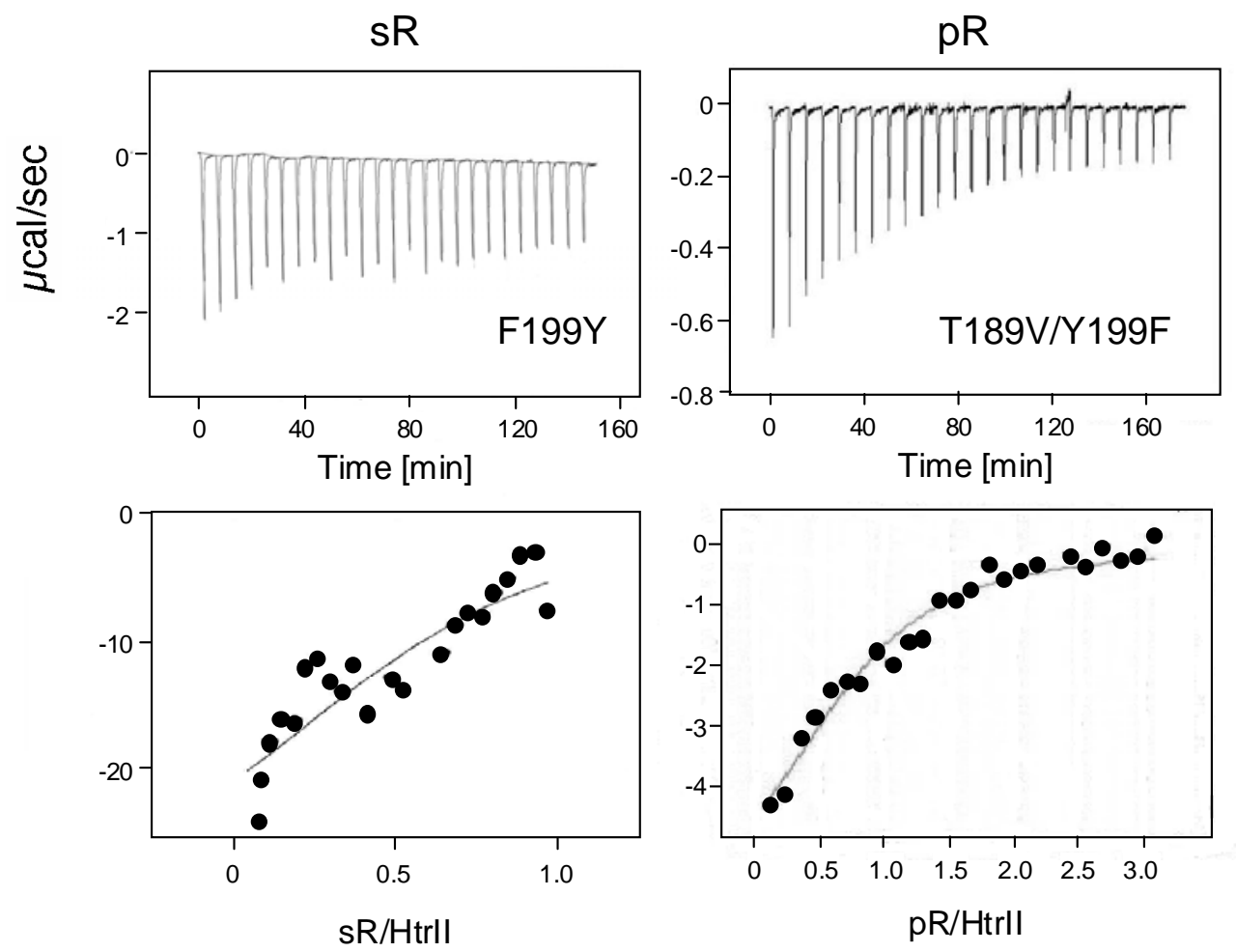

Sudo el al. 


\section{FIGURE 5}

a)
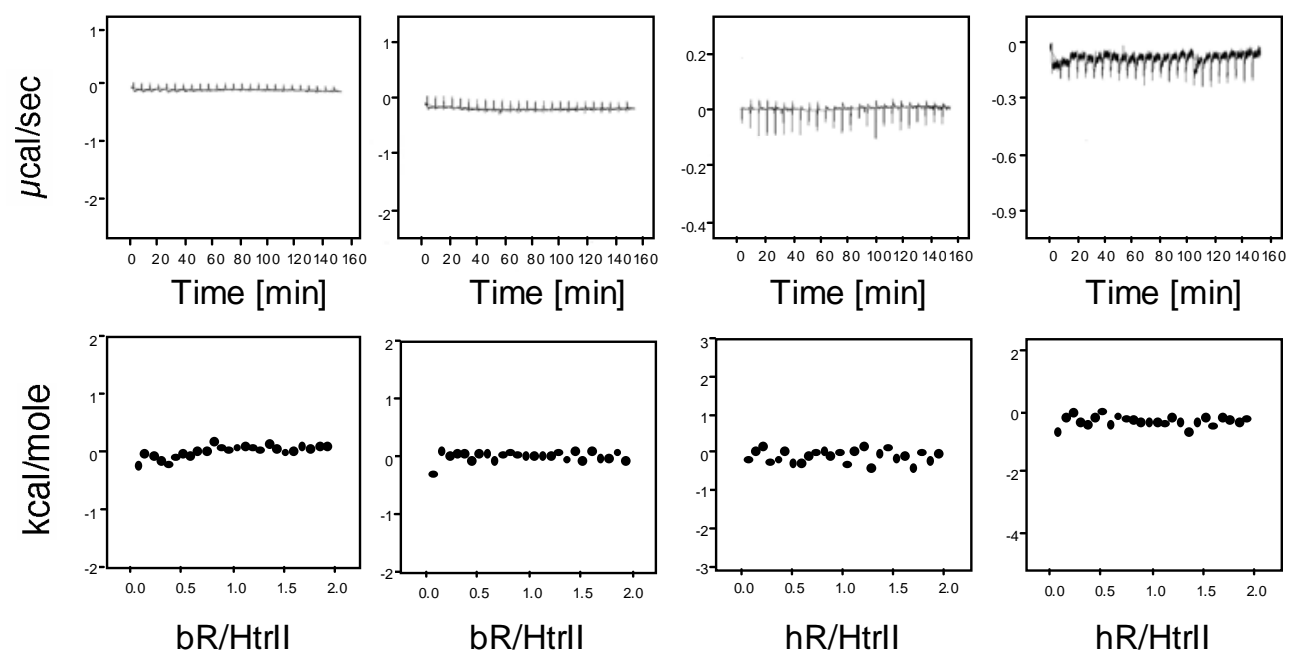

b)

bR $\mathrm{hR}$

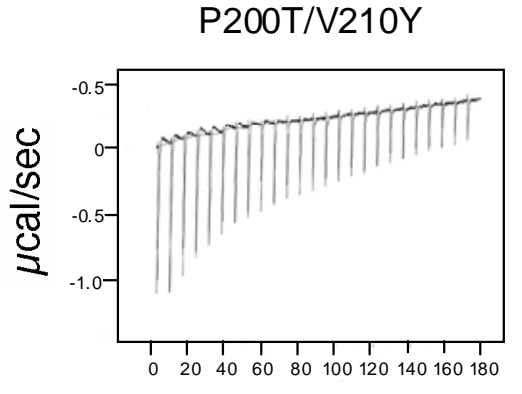
Time [min]

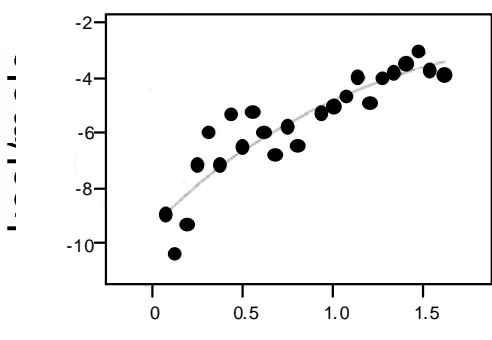

$\mathrm{bR} / p \mathrm{Htrll}$ P240T/F250Y

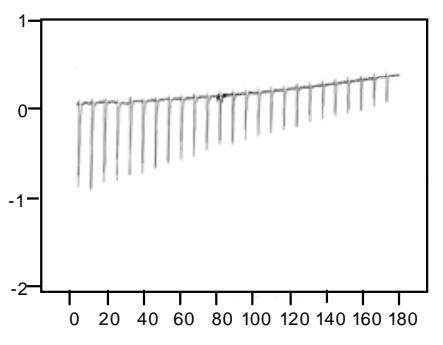

Time [min]

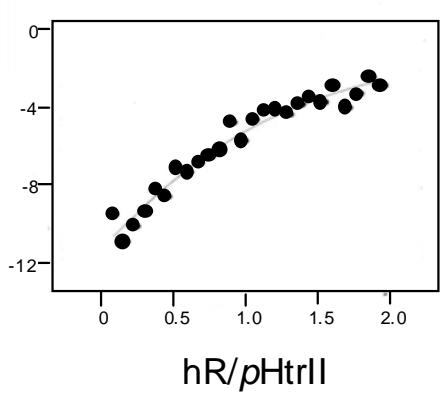


FIGURE 6

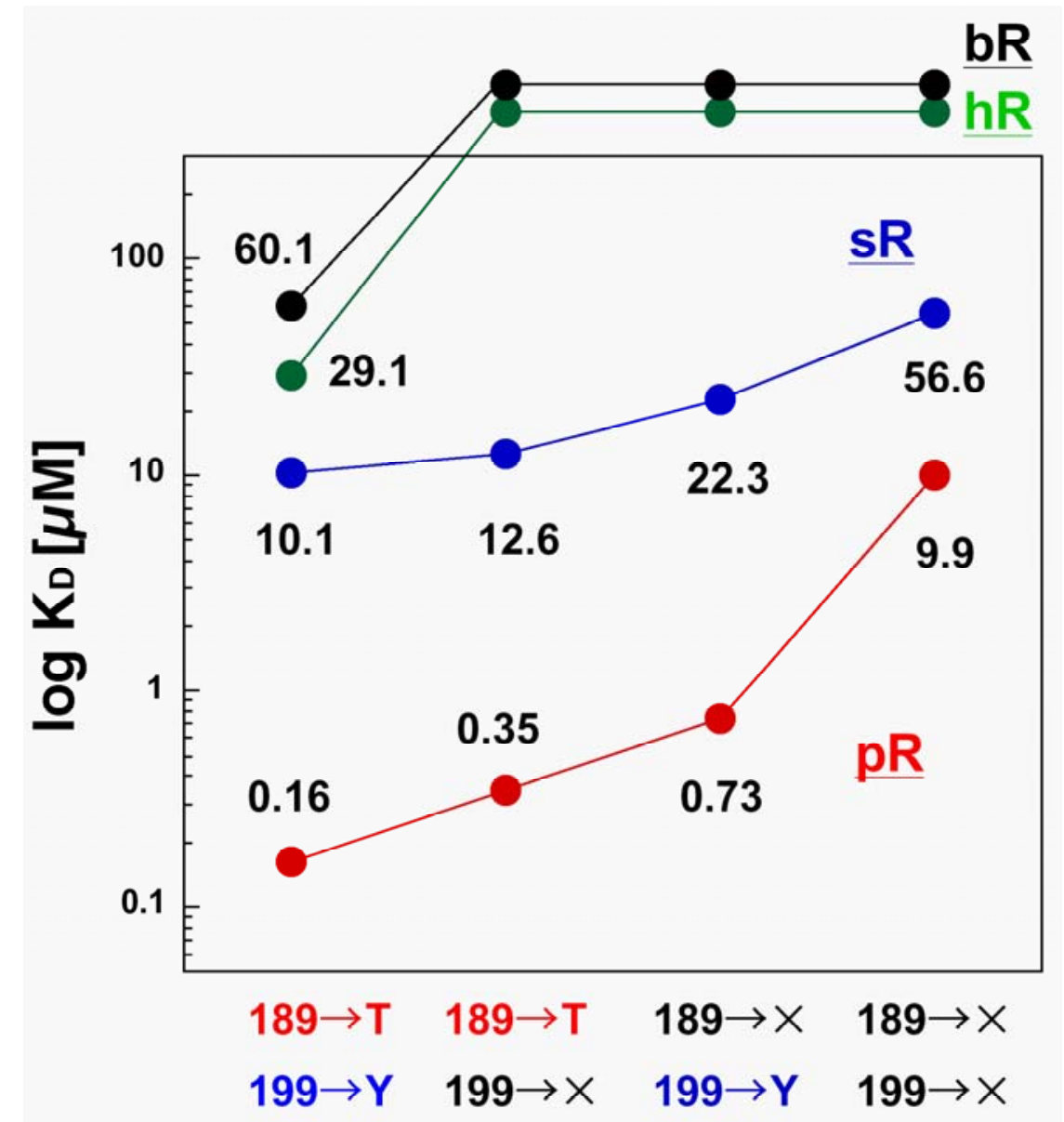

